\title{
Pancreatitis due to the total displacement of intragastric balloon to duodenu
}

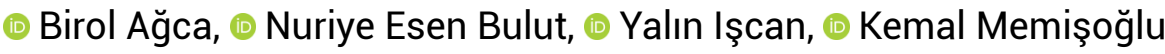 \\ Department of General Surgery, Fatih Sultan Mehmet Training and Research Hospital, İstanbul, Turkey
}

\begin{abstract}
Intragastric balloon (IGB) application in obesity treatment is an easily applied non-surgical method which has an effective weight loss potential. However, with increasing use in recent years, life-threatening complications have been reported in the literature. In addition to gastric perforation and intestinal obstruction due to serious complications, it has recently started to take its place in the literature. Thirteen cases of pancreatatitis due to IGB administration have been reported so far.In this study, a patient with morbid obese patient, acute abdominal pain and vomiting, who had intragastric balloon application five months ago, was evaluated.Biochemical and radiological work-up revealed total migration of the balloon to duodenum and acute pancreatitis due to compression effect.
\end{abstract}

Keywords: Acute pancreatitis; and balloon pancreatitis; intragastric balloon; obesity.

\section{Introduction}

Obesity is a serious public health problem which shortens the life-span and is accompanied by co-morbidities. ${ }^{[1]}$ Currently the only effective long-term treatment of morbid obesity is the bariatric surgery, which significantly reduces gastric capacity. ${ }^{[2]}$ The American Society for Metabolic and Bariatric Surgery reports a serious complication rate of $4 \%$ and mortality rate of $0.1 \%$ in morbid obesity surgery. [3] Therefore, other methods are used in obesity. These include dietary programs, exercise methods, and intragastric balloon (IGB) administration. Depending on the medical and socio-economic status of the patient, one or a combination of these methods may be used. IGB's which are used increasingly more due to ease of application and low cost not only cause early satiety due to mass occupying effect but also cause several hormonal changes leading to weight loss. ${ }^{[4]}$ IGB's should be kept in stomach up to 6 months to reduce $15-20 \%$ of total body weight in morbidly obese patients before bariatric surgery. As can be predicted, this will help to reduce morbidity risk due to weight loss before bariatric surgery. ${ }^{[5,6]}$ It should be kept in mind that implantation of IGB may cause some side effects most of which are related to gastric distention. Decreased gastric capacity causes nausea, vomiting and abdominal cramps. However tolerance rate of these symptoms is very high $(>90 \%){ }^{[7]}$ In addition to gastric perforation and intestinal obstruction, pancreatitis has also been reported in the literature as a serious complication. Up to now 13 cases of pancreatitis due to IGB administration have been reported..$^{[2,8]}$

We present a case of pancreatitis due to the migration of IGB which was administered to lose weight before 
bariatric surgery to the second part of duodenum under the light of current literature.

\section{Case Report}

Approximately 5 months ago an intragastric balloon (MEDSIL, Novomytishchinsk, Russia) was applied to a 50 -year old morbid obese (body mass index (BMI) $=52 \mathrm{~kg} /$ $\mathrm{m}^{2}$ ) woman who was being treated with diet and exercise for preparation to bariatric surgery. The patient who presented to our emergency clinic because of sudden onset of abdominal pain and vomiting had generalized tenderness in the epigastric region on physical examination. Blood work-upwas as follows: leukocyte: $13600 / \mathrm{mm}^{3}$, blood sugar: $111 \mathrm{mg} / \mathrm{dL}$, amylase: $3908 \mathrm{U} / \mathrm{L}$, lipase: $16762 \mathrm{U} / \mathrm{L}$, Calcium (Ca): $8.4 \mathrm{mg} / \mathrm{dL}$ and lactate dehydrogenase: 193 $\mathrm{U} / \mathrm{L}$; Cholesterol, triglycerides, bilirubin, and alkaline phosphatase were normal. In her abdominal tomography there was edema at pancreas parenchyma. Radiology also reported an $8 \times 5 \mathrm{~cm}$ diameter cystic mass with an unknown origin next to pancreas head and stomach antrumpylorus which has a cystic density and contrast involving wall. No pathological appearance was observed at gallbladder location (Fig. 1a). The patient was hospitalized and treatment was initiated for pancreatitis. Because there was a history of IGB, balloon pancreatitis was thought as the diagnosis and early intervention was decided. After the necessary preparations the patient was transferred to endoscopy unit. The patient was informed about the subject and an consent form was obtained. Under sedation upper gastrointestinal system endoscopy was performed. No gastric balloon was seen in endoscopy (Fig. 1b). When the endoscope was inserted through the pyloric channel, the balloon was observed to slide down the second part of duodenum obstructing it near totally (Fig. 1c). In the duodenum mucosa, erosions were detected locally due to balloon compression. The balloon was first blasted by a needle, the content of the balloon was evacuated into the stomach and then aspirated. The balloon was caught with a biopsy forceps and removed under endoscopic vision. The patient's symptoms regressed after the procedure amylase and lipase values decreased (from 3908 to 46 U/L, and from 16762 to $185 \mathrm{U} / \mathrm{L}$, respectively).
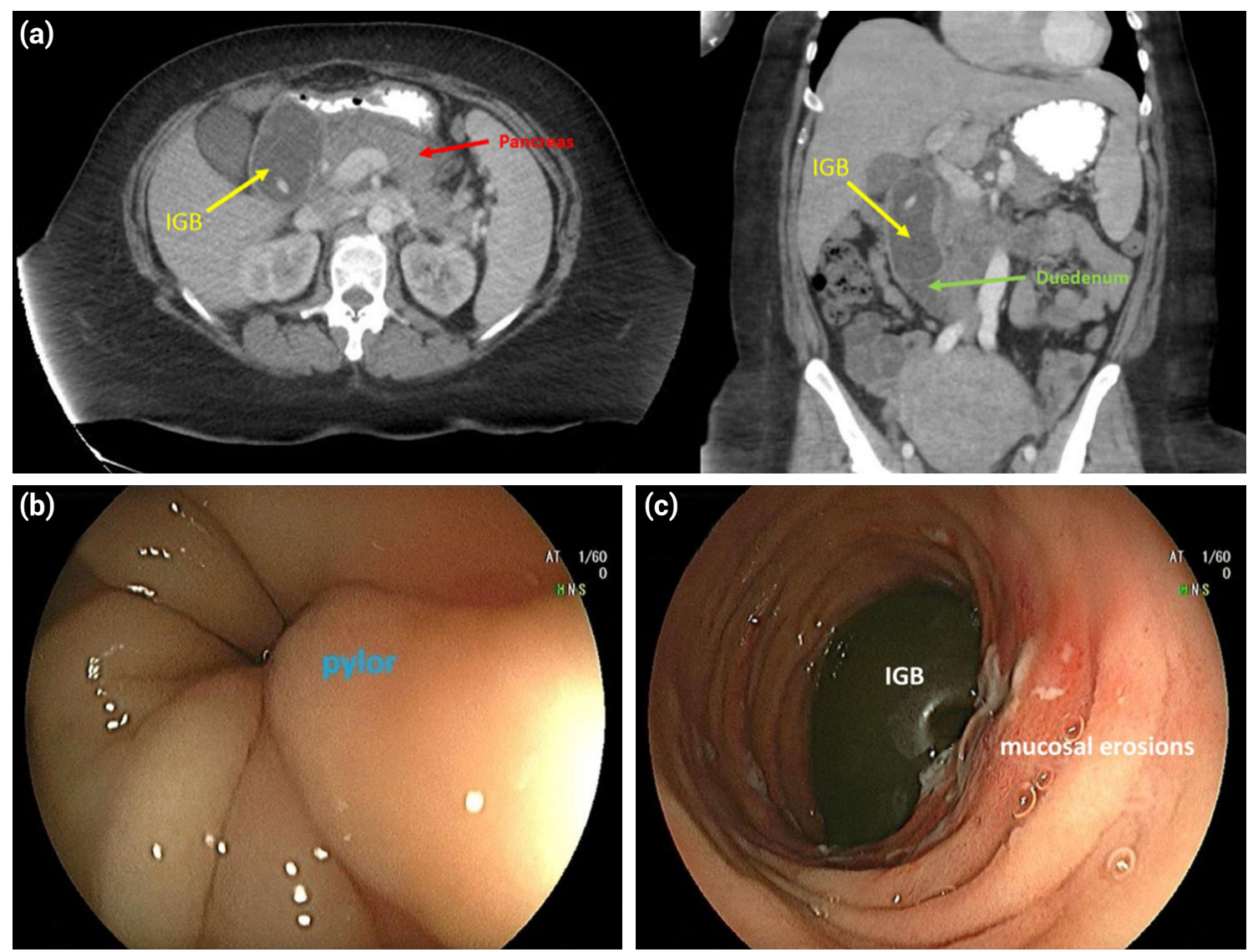

Figure 1. (a) CT showing IGB in the duodenum(yellow arrow )compressing head of the pancreas (green arrow)with peripancreatic oedema and stranding (red arrow). (b) IGB does not appear in the stomach. (c) The entire intra-gastric balloon appears in the second part of the duodenum. 


\section{Discussion}

Endoscopic IGB administration is increasingly used because it provides a less invasive and relatively safe option to achieve short-term weight loss. ${ }^{[9]}$ The effectiveness of this method varies according to various clinical studies. In one study, loss of $11.2-12.8 \mathrm{~kg} 3$ months after application of IGB and $16.7-20.0 \mathrm{~kg}$ after 6 months were obtained. ${ }^{[10]}$ In another study, loss of only $5.9 \mathrm{~kg}$ after 6 monthswasdetected. ${ }^{[11]}$ Thisindicatedthatthe efficiency is variable. In our patient BMI was $52 \mathrm{~kg} / \mathrm{m}^{2}$ before the balloon and she lost $7.2 \mathrm{~kg}$ in 5 months (BMI $50 \mathrm{~kg} / \mathrm{m}^{2}$ ) which is consistent with the literature.

Although endoscopic placement of IGB is considered safe and relatively easy when compared with surgical treatment of obesity, patient tolerance is one of the most important constraints for the use of this treatment modality. ${ }^{[7]}$ Most balloon-related side effects are associated with gastric distention and reduced gastric capacity, which are directly related to balloon size. ${ }^{[12,13]}$ In addition, ulcers, erosions, severe esophagitis and perforations in the stomach and duodenum have also been reported..$^{[7,11]}$

The absence of severe side effects in the first months in our patient indicates that the balloon is well tolerated and the symptoms in last few days are completely related to the migration of the balloon. Although complications during IGB treatment may appear at an early or late period, most patients may experience temporary abdominal pain, nausea, and vomiting after insertion of the balloon. ${ }^{[1]}$ Clinically significant acute pancreatitis with radiological and biochemical (hyperamylasemia) parameters are considered as evidence for effects of the balloon on pancreas. ${ }^{[7]}$ Remission of symptoms and normalization of amylase after removal of IGB contribute more to the diagnosis. When the literature is examined, the development of acute pancreatitis has been seen at various times, from 2 days to 11 months, and in our case this period was 5 months. ${ }^{[1]}$ Findings that support acute pancreatitis in clinical, radiological, and biochemical tests should suggest acute pancreatitis due to balloon compression and the first option should be the removal of the balloon with endoscopy. The balloon was successfully removed by endoscopy in the second day of hospitalization.

Between 2008 and 2012, only three cases of balloon pancreatitis were reported but this number has reached to 10 since 2014. The reason for this increase may be the more frequent use of this method in recent years. ${ }^{[8]}$ The pancre- atitis cases seen in the literature can be attributed to the mass effect of the balloon on the pancreas or to the migration of balloon to the second part of the duodenum. ${ }^{[14]}$

The difference of our case from the other causes of acute pancreatitis in the literature was it was not due to intragastric compression effect but instead due tocompression of the whole balloon from intra-duodenal area directly to pancreatic head. The most striking feature of our case was the placement of the entire balloon to the second part of duodenum after passage from pylorus and its adaptation to duodenum.

\section{Conclusion}

In conclusion balloon pancreatitis should be kept in mind in patients who develop symptoms such as abdominal pain and nausea at $2^{\text {nd }}$ day to $11^{\text {th }}$ month after insertion of intragastric balloon after other causes of acute pancreatitis are excluded. Although this condition is very rare it is seen increasingly more. The diagnosis is generally made after compression is confirmed with crosssectional imaging. Removal of the balloon with rapid endoscopic intervention rapidly improves the clinical picture and decreases the risk of serious complications and sequelae.

\section{Disclosures}

Informed Consent: Written informed consent was obtained from the patient for the publication of the case report and the accompanying images.

Peer-review: Externally peer-reviewed.

Conflict of Interest: None declared.

\section{References}

1. Aljiffry M, Habib R, Kotbi E, Ageel A, Hassanain M, Dahlan Y. Acute Pancreatitis: A Complication of Intragastric Balloon. Surg Laparosc Endosc Percutan Tech 2017;27:456-9.

2. Tate $\mathrm{CM}$, Geliebter A. Intragastric Balloon Treatment for Obesity: Review of Recent Studies. Adv Ther 2017;34:1859-75.

3. Hamilton A. Metabolic and bariatric surgery: American Society for Metabolic and Bariatric Surgery. 2013. https://asmbs. org/app/uploads/2014/05/Metabolic+Bariatric-Surgery.pdf.

4. Phillips RJ1, Powley TL. Gastric volume rather than nutrient content inhibits food intake. Am J Physiol 1996;271(3 Pt 2):R766-9.

5. Imaz I, Martínez-Cervell C, García-Alvarez EE, Sendra-Gutiérrez JM, González-Enríquez J. Safety and effectiveness of the intragastric balloon for obesity. A meta-analysis. Obes Surg 2008;18:841-6. [CrossRef] 
6. Mathus-Vliegen EM1, Tytgat GN. Intragastric balloons for morbid obesity: results, patient tolerance and balloon life span. Br J Surg 1990;77:76-9. [CrossRef]

7. Mohammed AE, Benmousa A. Acute pancreatitis complicating intragastric balloon insertion. Case Rep Gastroenterol 2008;2:291-5. [CrossRef]

8. Gore N, Ravindran P, Chan DL, Das K, Cosman PH. Pancreatitis from intra-gastric balloon insertion: Case report and literature review. Int J Surg Case Rep 2018;45:79-82. [CrossRef]

9. ASGE Bariatric Endoscopy Task Force and ASGE Technology Committee, Abu Dayyeh BK, Kumar N, Edmundowicz SA, Jonnalagadda S, Larsen M, Sullivan S, et al. ASGE Bariatric Endoscopy Task Force systematic review and meta-analysis assessing the ASGE PIVI thresholds for adopting endoscopic bariatric therapies. Gastrointest Endosc 2015;82:425-38.e5.
10. Mathus-Vliegen EM, Tytgat GN. Intragastric balloon for treatment-resistant obesity: safety, tolerance, and efficacy of 1-year balloon treatment followed by a 1-year balloon-free follow-up. Gastrointest Endosc 2005;61:19-27. [CrossRef]

11. Ganesh R, Rao AD, Baladas HG, Leese T. The Bioenteric Intragastric Balloon (BIB) as a treatment for obesity: poor results in Asian patients. Singapore Med J 2007;48:227-31.

12. Geliebter A, Westreich S, Gage D. Gastric distention by balloon and test-meal intake in obese and lean subjects. Am J Clin Nutr 1988;48:592-4. [CrossRef]

13. Geliebter A. Gastric distension and gastric capacity in relation to food intake in humans. Physiol Behav 1988;44:665-8.

14. Öztürk A, Yavuz Y, Atalay T. A Case of Duodenal Obstruction and Pancreatitis Due to Intragastric Balloon. Balkan Med J 2015;32:323-6. [CrossRef] 